\title{
Hydrogen Gas Sensor Based Upon Proton Acceptors Integrated in Copper-Tetra-2,3-Pyridinoporphyradine
}

\author{
T. Hoki, H. Takahashi, S. Suzuki, and J. Mizuguchi
}

\begin{abstract}
We have previously developed a novel $\mathrm{H}_{2}$ gas sensor based upon a high proton affinity of diketodipyridylpyrrolopyrrole. Protonation is found to bring about a remarkable reduction of the electrical resistivity and this effect has been applied to $\mathrm{H}_{2}$ gas sensors. In the present investigation, an attempt was made to integrate proton acceptors (i.e., pyridyl rings) into copperphthalocyanine in order to improve the sensor characteristics. The present sensor exhibits a remarkable change in electrical resistivity by three orders of magnitude even under $0.01 \% \mathrm{H}_{2}$. Furthermore, the sensor is found to operate reversibly at room temperature and is scarcely influenced by ambient gases such as $\mathrm{CH}_{4}, \mathrm{CO}, \mathrm{CO}_{2}$, $\mathrm{NO}, \mathrm{SO}_{2}, \mathrm{CH}_{3} \mathrm{OH}, \mathrm{C}_{2} \mathrm{H}_{5} \mathrm{OH}$, and $\mathrm{H}_{2} \mathrm{O}$ moisture.
\end{abstract}

Index Terms-Copperphthalocyanine (CuPc), hydrogen sensor, proton affinity, pyridyl ring.

\section{INTRODUCTION}

$\mathbf{F}$ UEL CELLS based upon $\mathrm{H}_{2}$ have recently attracted attention as a clean energy source for the future [1]. However, hydrogen is the smallest atom and, thus, the $\mathrm{H}_{2}$ gas can leak easily. In addition, it can catch fire, for example, from a spark. For this reason, reliable, inexpensive $\mathrm{H}_{2}$ gas sensors are in great demand. The sensors based on a catalytic combustion [2], [3] as well as on an oxide semiconductor such as $\mathrm{SnO}_{2}$ [2], [4] are two major products used widely in various industrial environments. The former utilizes a combustion heat of $\mathrm{H}_{2}$ with $\mathrm{O}_{2}$ in air; whereas the latter relies on the change in electrical resisitivity due to $\mathrm{H}_{2}$ in combination with a molecular sieve for $\mathrm{H}_{2}$. These sensors operate, however, in a limited range of $\mathrm{H}_{2}$ between several $10 \mathrm{ppm}$ and $4 \% \mathrm{H}_{2}$ (i.e., the LEL: lower explosion limit). In addition, the sensor requires external heating of about $200{ }^{\circ} \mathrm{C}-350^{\circ} \mathrm{C}$ for the proper operation. Another type of the sensor is based upon field effect transistor (FET) [5] which utilizes a Pd or its alloy as the gate electrode. However, the output signal becomes rapidly saturated as the $\mathrm{H}_{2}$ concentration exceeds $1 \%$. On the other hand, a novel surface acoustic wave (SAW) type sensor prepared on a piezoelectric material functions in a wide rage between $10 \mathrm{ppm}$ and $100 \% \mathrm{H}_{2}$ [6]. Again, the present sensor requires external heating of about $130^{\circ} \mathrm{C}$ in order to achieve a quick response of about $4 \mathrm{~s}$.

In the course of our investigation on electronic structure of diketodiphenylpyrrolopyrroles known as red pigments [7], we encountered a high proton affinity of 3,6-bis(4'-pyridyl)-pyrrolo[3,4-c]pyrrole-1,4-dione [ $p$-DPPP:

Manuscript received May 9, 2006; revised August 3, 2006; accepted August 11,2006 . The associate editor coordinating the review of this paper and approving it for publication was Dr. Subhas Mukhopadhyay.

The authors are with the Department of Applied Physics, Yokohama National University, Hodogaya-ku, 240-8501 Yokohama, Japan (e-mail: mizu-j@ynu.ac.jp; takahasi@ynu.ac.jp; s-suzuki@ynu.ac.jp).

Digital Object Identifier 10.1109/JSEN.2007.894155
Fig. 1(a)] due to the $\mathrm{N}$ atoms of the pyridyl rings [8]. Interesting to say, protonation at the $\mathrm{N}$ atom brings about a drastic color change from red to violet, accompanied by a reduction in electrical resistivity by five orders of magnitude, as well as the appearance of photoconduction [8]. Among these outstanding effects, we focused especially on the resistivity change for potential applications to acid sensors. Later, however, we found it more fruitful to transform the acid sensor into a $\mathrm{H}_{2}$ gas sensor in view of the advent of the fuel cell in the near future. We believed that $\mathrm{H}_{2}$ can be dissociated into atomic hydrogens even in the solid state in the presence of a small amount of Pd or Pt (used as a hydrogen trap) in combination with an application of a high electric field of about $10^{5} \mathrm{~V} / \mathrm{cm}$. Then, the atomic hydrogen $(\mathrm{H})$ protonates $p$-DPPP at the $\mathrm{N}$ atom of the pyridyl ring to simultaneously release an electron that contributes to the electrical current: $\mathrm{H}+$ pyridyl ring $\rightarrow$ protonated pyridyl ring $\left(\mathrm{N}^{+} \mathrm{H}\right)+\mathrm{e}^{-}$. We have realized these ideas in interdigital electrodes, as shown in Fig. 2(a) where a trace of Pd or Pt is directly sputtered onto ITO (indium-tin-oxide) electrodes in the form of islands (ca. $3 \AA$ ) [Fig. 2(b)] [9], [10]. Then, $p$-DPPP layer is applied by vacuum evaporation (ca. $300 \AA$ ). $\mathrm{H}_{2}$ is first adsorbed on the surface of $p$-DPPP and diffuses into the bulk, where $\mathrm{H}_{2}$ encounters sputtered $\mathrm{Pd}$. Then, $\mathrm{H}_{2}$ becomes unstable on $\mathrm{Pd}$ and dissociates into hydrogen atoms assisted by a high electric field: $\mathrm{H}_{2} \rightarrow \mathrm{H}+\mathrm{H}$. At this moment, the $\mathrm{N}$ atom of the pyridyl ring captures the proton, ending up with a release of one electron. The sensor exhibits a remarkable reduction in resistivity by two orders of magnitude even under $0.05 \% \mathrm{H}_{2}$ [9].

Next, an attempt was made to extend our idea to a larger chromophore such as perylene-imide derivatives with two pyridyl rings [11] [Fig. 1(b)]. The present sensor exhibits even a higher sensitivity than that of $p$-DPPP by one order of magnitude.

A further trial was made in the present investigation to integrate pyridyl rings, in place of phenyl rings, at the peryphery of the copperphthalocyanine ( $\mathrm{CuPc})$, as shown in Fig. 1(c). Four pyridyl rings are directly connected to the macrocyclic ring system composed of $18 \pi$-electrons. The present paper describes the synthesis of $\mathrm{Cu}-\mathrm{PPc}$ and the performance of the $\mathrm{H}_{2}$ sensor.

\section{EXPERIMENT}

\section{A. Preparation of $\mathrm{Cu}-\mathrm{PPc}$ and Its Purification}

$\mathrm{Cu}-\mathrm{PPc}$ was synthesized according to the reaction scheme shown in Fig. 3. 2,3-Pyridinedicarboxyrate $(8.46 \mathrm{~g}, 56.7 \mathrm{mmol})$, urea $(10.0 \mathrm{~g}, 166.7 \mathrm{mmol})$, and copper (I) chloride (1.55 g, $15.6 \mathrm{mmol}$ ) were heated at $200^{\circ}$ in trichlorobenzene $(200 \mathrm{ml})$ in the presence of hexa-ammonium heptamolybdate tetrahydrate $(0.032 \mathrm{~g}, 0.026 \mathrm{mmol})$ as the catalyst. The product was filtered 
(a)<smiles>O=C1NC(c2ccncc2)=C2C(=O)NC(c3ccncc3)=C12</smiles>

(b)

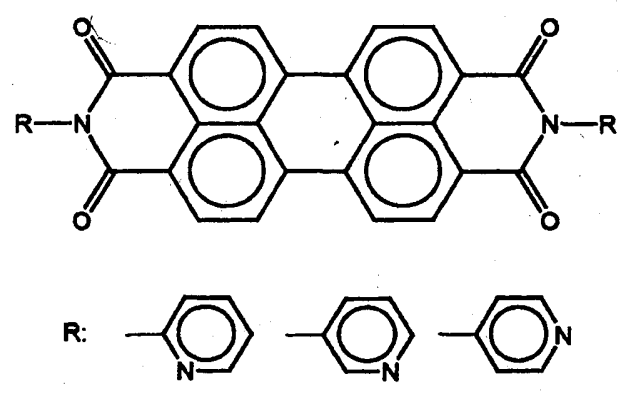

(c)

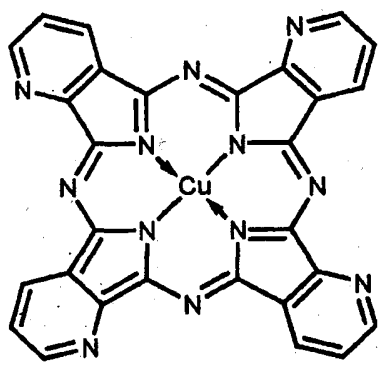

Fig. 1. Molecular conformation: (a) Diketodipyridylpyrrolopyrrole, (b) perylene-imide derivatives with pyridyl rings, and (c) copper-tetra-2,3-pyridinoporphyradine $(\mathrm{Cu}-\mathrm{PPc})$.

(a)

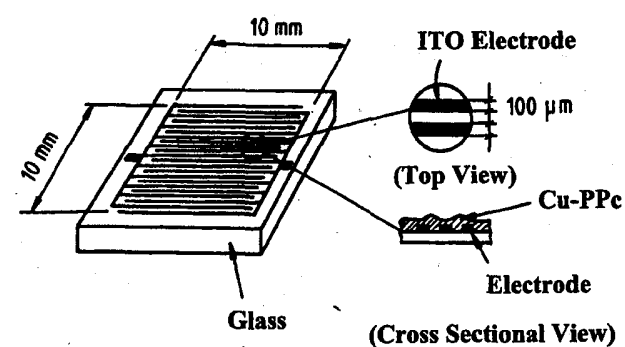

(b)

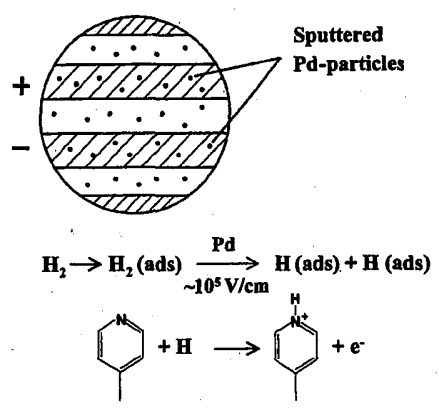

Fig. 2. (a) Interdigital electrodes. (b) Magnified Pd-sputtered electrodes.

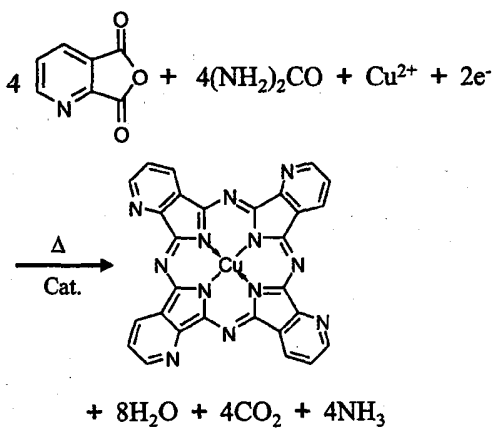

Fig. 3. Reaction scheme for the synthesis of Cu-PPc.

and washed with toluene and methanol, and then boiled with $1 \mathrm{~N} \mathrm{HCl}$ and $1 \mathrm{~N} \mathrm{NaOH}$ solutions to eliminate impurities such as unreacted cuprous salts. Finally, $4.5 \mathrm{~g}$ of the crude product was obtained in $54.6 \%$ yield based upon 2,3-pyridinedicarboxyrate.

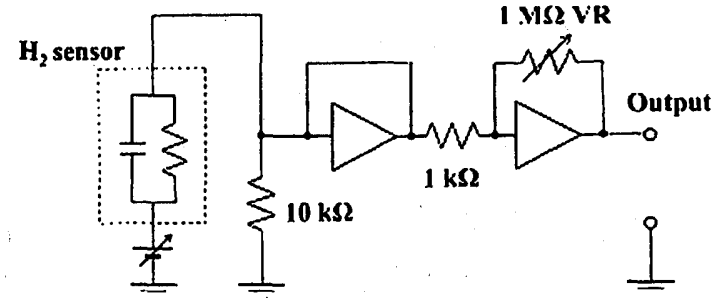

Fig. 4. Experimental setup for measurements of the sensor characteristics.

The product was then purified by sublimation under vacuum, using a two-zone furnace [12].

\section{B. Equipment}

UV-VIS absorption spectra were recorded on a UV-2400PC spectrophotometer from Shimadzu. Thermogravimetric analysis and differential thermal analysis (TGA/DTA) measurements were made on powdered samples under vacuum by means of a Rigaku Thermo Plus 2 TG-8120 at a heating rate of $10{ }^{\circ} \mathrm{C} / \mathrm{min}$.

\section{Fabrication of Sensors}

The interdigital electrodes as shown in Fig. 2(a) were prepared by photolithographic technique. The electrodes were made of indium-tin-oxide (ITO). An extremely small amount of Pd was then sputtered directly onto the electrodes (E-1030 Ion Sputter from Hitachi Corporation) in such a way as to form islands of Pd so as to avoid their contacts. The optimum thickness of Pd layer is about $3 \AA$. Then, a thin layer of $\mathrm{Cu}-\mathrm{PPc}$ was applied by vacuum evaporation to the thickness of about $100 \AA$ (Tokyo Vacuum Company, Ltd.: model EG240).

\section{Measurements of the Sensor Performance}

Fig. 4 shows the experimental setup for measurements of the electrical resistivity. The current induced upon exposure to $\mathrm{H}_{2}$ was passed through a resistance of $10 \mathrm{k} \Omega$ connected in series with a bias voltage supply, and the voltage generated was then amplified by about $10^{3}$ times. Fig. 5 illustrates the sample chamber used for the study of the influence of various gases on the sensor characteristics. Measurements were made with a flow rate of $21 / \mathrm{min}$. 


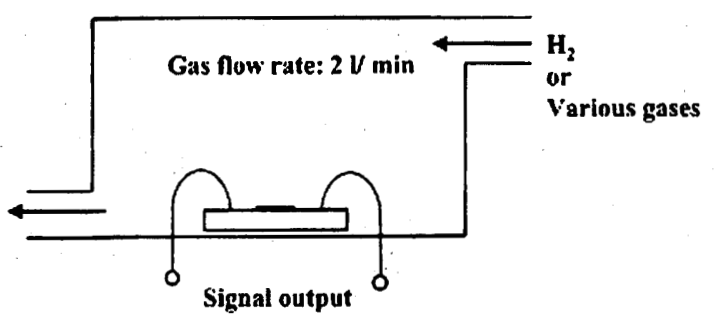

Fig. 5. Sample chamber for measurements of the effect of ambient gases on the sensor characteristics.

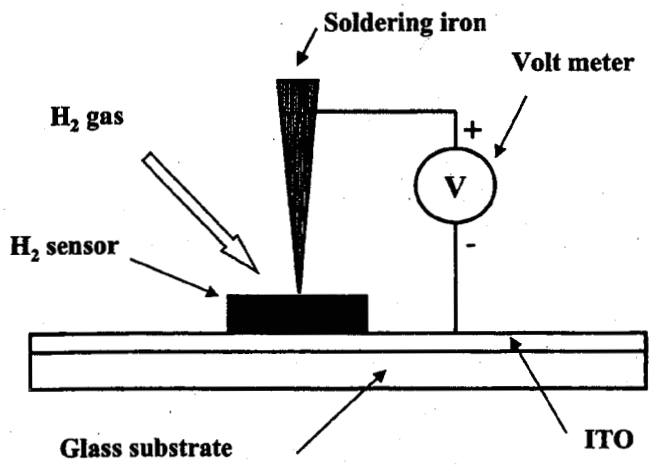

Fig. 6. Experimental setup for measurements of the Seebeck effect.

\section{E. Experimental Setup for Measurements of the Seebeck Effect}

Fig. 6 shows the experimental setup for measurements of the Seebeck effect [13], [14]. This method serves as a good means to determine the charge carrier in high-resistive materials and evaluates thermoelectric power which appears between hot and cold ends of a material. The hot end is made by a soldering iron with a small spring on top maintained at $100^{\circ} \mathrm{C}$; whereas the cold end is the ITO electrode at room temperature. If the potential of the hot end is positive, then the carrier is electrons. Similarly, if the potential is negative, the charge carrier is due to holes.

Since the measurement of the Seebeck effect requires a temperature gradient along the direction of the film thickness (Fig. 6), the $\mathrm{Cu}-\mathrm{PPc}$ layer of the $\mathrm{H}_{2}$ gas sensor was prepared thicker (about $1200 \AA$ ) than the standard one (about $100 \AA$ ). Because of this, the present sensor was much less sensitive by about two to three orders of magnitude than the standard one. This tradeoff is required for meaningful measurements of the Seebeck effect.

\section{F. Molecular Orbital (MO) Calculations}

MO calculations provide information about the heat of formation (i.e., stability) of a molecule. The response time of the sensor after $\mathrm{H}_{2}$ is off is considered to be closely correlated to the stability of protonated $\mathrm{Cu}-\mathrm{PPc}$. If the heat of formation of protonated species is much higher than that of the initial state, the decay process seems to proceed rapidly by immediately giving up protons. For this reason, the heat of formation of the initial and protonated species can be a good measure for the study of the decay process. (a)

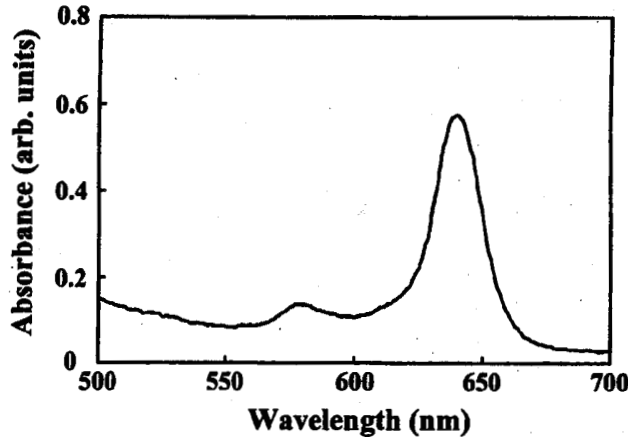

(b)

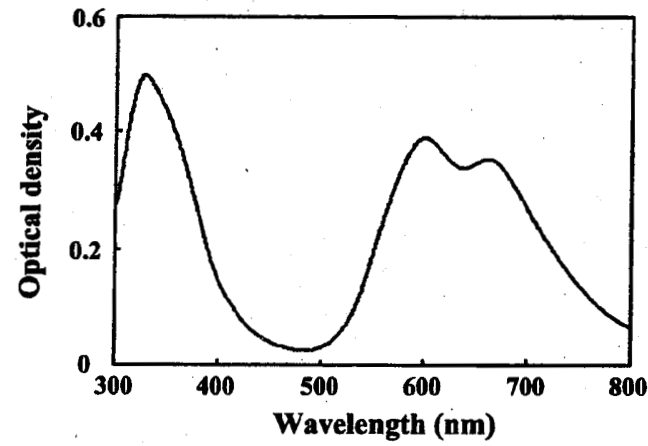

(c)

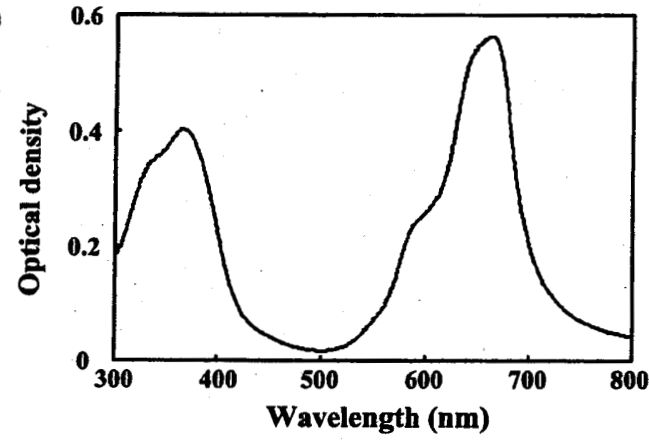

Fig. 7. Spectrum (a) is the solution spectrum of $\mathrm{Cu}-\mathrm{PPc}$ in dimethylsulfoxide, and spectra (b) and (c) are the absorption spectra of evaporated $\mathrm{Cu}-\mathrm{PPc}$ before and after protonation, respectively.

As a matter of fact, calculations should be made on $\mathrm{Cu}-\mathrm{PPc}$. However, no appropriate parameters for the $\mathrm{Cu}$ atom are available in the WinMOPAC program package [15]. In addition, $\mathrm{Cu}-\mathrm{PPc}$ does not represent a completely saturated entity (closed shell) like metal-free-PPc. Therefore, metal-free PPc was used as the substitute for $\mathrm{Cu}-\mathrm{PPc}$. MO calculations were carried out by optimizing geometry for the initial as well as variously protonated states of metal-free PPC by means of the AM1 Hamiltonian in the WinMOPAC program package [15].

\section{RESULTS AND DISCUSSION}

\section{A. Characterization of $\mathrm{Cu}-\mathrm{PPc}$ in Solution and in the Solid State}

Fig. 7(a) shows the solution spectrum in dimethylsulfoxide. The solution spectrum exhibits one single absorption band around $640 \mathrm{~nm}$, which is typical of metal phthalocyanine compounds as characterized by $D_{4 h}$ symmetry [7]. On the 


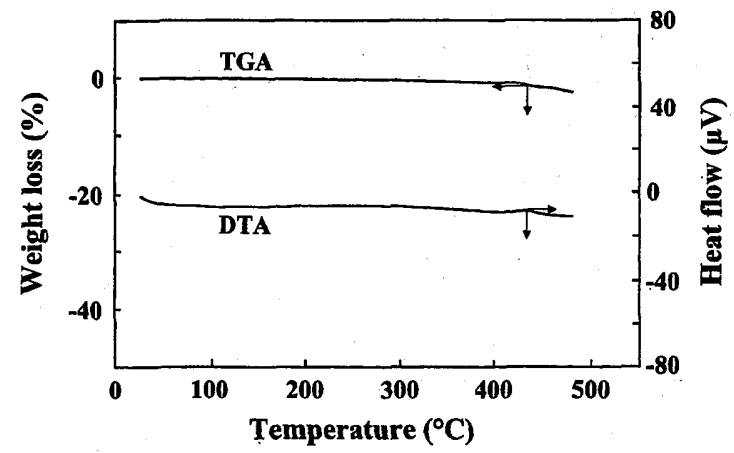

Fig. 8: TGAVTA curves measured on powdered $\mathrm{Cu}-\mathrm{PPc}$ under vacuum

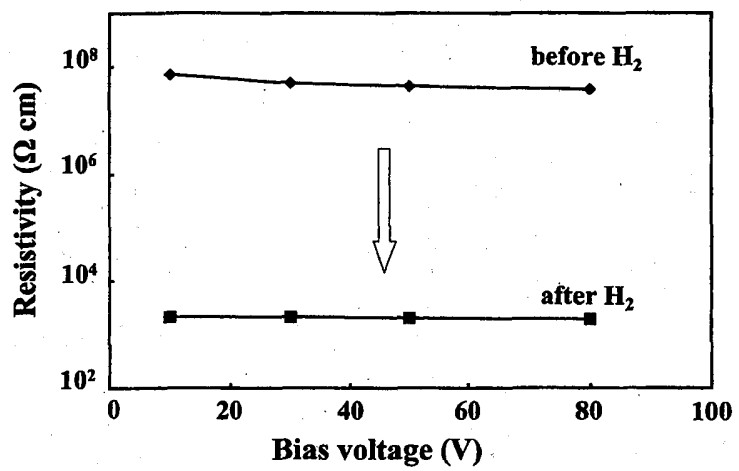

Fig. 9. Change in electrical resistivity of the sensor as a function of applied voltage before and after introduction of $\mathrm{H}_{2}$.

other hand, Fig. 7(b) and (c) shows the solid-state spectra of evaporated $\mathrm{Cu}$-PPc before and after protonation with the vapors of nitric acid. This is a model experiment of the $\mathrm{H}_{2}$ gas sensor and how the optical absorption changes when the sensor captures protons. The absorption spectrum before protonation is basically quite similar to that of $\mathrm{CuPc}$ [7]. Then, protonation brings about a spectral change in such a way that the intensity of the two visible bands was reversed.

Fig. 8 shows the TGA/DTA curves of $\mathrm{Cu}-\mathrm{PPc}$ under vacuum. $\mathrm{Cu}-\mathrm{PPc}$ is surprisingly stable up to about $500^{\circ} \mathrm{C}$, which exceeds even the thermal stability of CuPc (around $450^{\circ} \mathrm{C}$ ) known as the most stable phthalocyanine [7].

\section{B. Performance of the $\mathrm{H}_{2}$ Gas Sensor}

Fig. 9 shows the change in electrical resistivity of the sensor as a function of bias voltage when the sensor is exposed to $100 \%$ $\mathrm{H}_{2}$. The resistivity decreases drastically by four orders of magnitude at room temperature. The present sensitivity is nearly equivalent to that of perylene-imide derivatives [11] and is better than that of $p$-DPPP by one order of magnitude [9]. Furthermore, bias-voltage dependence is scarcely observed, indicating the ohmic contact between Cu-PPc and ITO-electrodes.

Fig. 10 shows the sensitivity of the sensor as a function of $\mathrm{H}_{2}$ concentration $(0.01 \%, 0.05 \%, 0.1 \%, 1 \%$, and $100 \%)$, where the resistivity and the $\mathrm{H}_{2}$ concentration are displayed in a $\log -\log$ plot. The resistivity change of three orders of magnitude is observed under $0.01 \% \mathrm{H}_{2}$. Furthermore, the resistivity is found to decrease linearly with increasing $\mathrm{H}_{2}$ concentration.

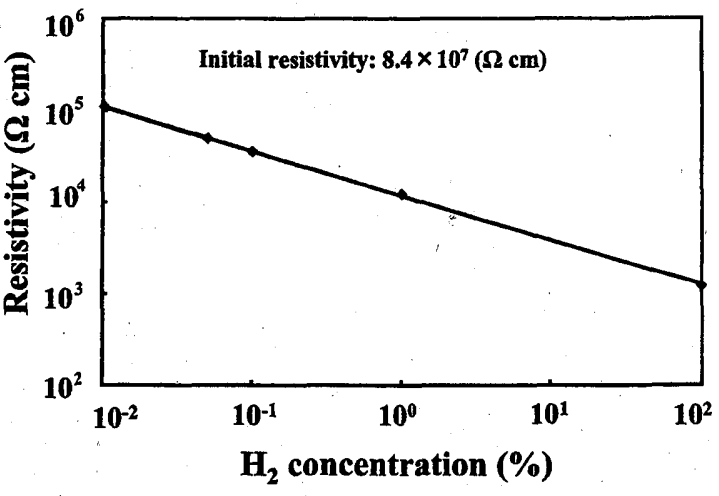

Fig. 10. $\log -\log$ plot between the resistivity of the sensor and the $\mathrm{H}_{2}$ concentration.

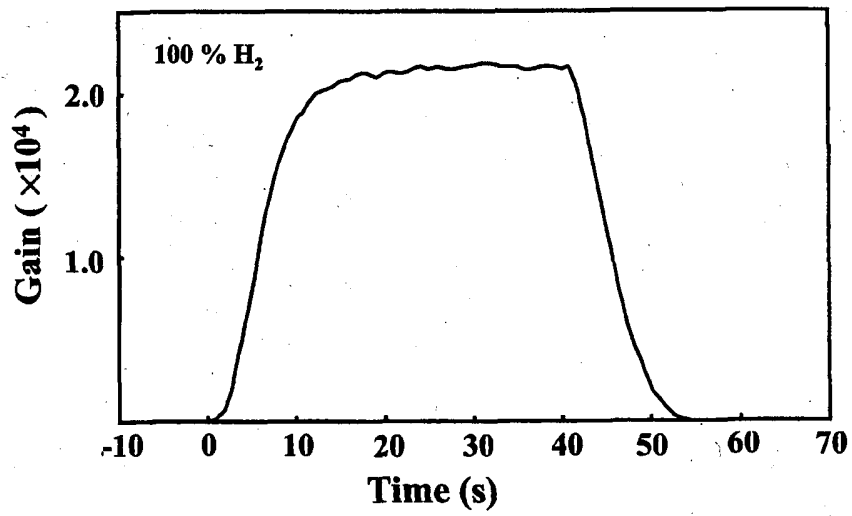

Fig. 11. Buildup and build-down of the $\mathrm{Cu}-\mathrm{PPc}$ sensor as a function of time.

The response time of the sensor is shown in Fig. 11. The maximum gain is about 22500 , where the gain is defined as the ratio of the initial resistivity to the final one. The build-up and build-down time ( $80 \%$ of maximum value) amount to about $8 \mathrm{~s}$. However, the gain change in several factors is sufficient for the detection of $\mathrm{H}_{2}$, and thus the sensor response is quite rapid. An additional appearing point is the reversibility of the sensor as characterized by the fast decay of the signal when $\mathrm{H}_{2}$ is switched off.

The decay is likely to proceed as a result of $\mathrm{H}_{2}$ desorption: $\mathrm{H}^{+}$(ads) $+\mathrm{e}^{-} \rightarrow 1 / 2 \mathrm{H}_{2}$. Whether desorption occurs with ease or with difficulty can be closely correlated to the stability of protonated species. Table I shows the heat of formation of variously protonated metal-free PPc at the $\mathrm{N}$ atom as deduced from $\mathrm{MO}$ calculations, where the heat of formation serves as a measure of the stability. It is apparent that the heat of formation increases significantly as the extent of protonation proceeds from mono to tetra protonation. In other words, protonated species have a tendency to give up protons as quick as possible and come back to the initial state. This could explain why the decay process is quite rapid in $\mathrm{Cu}-\mathrm{PPc}$. However, the present interpretation is not yet conclusive and requires further investigation.

\section{Influence of Various Gases on the Sensor}

As judged from the operation principle of our sensor described in Section I, the sensor is expected to be quite inert 
TABLE I

HEAT OF FORMATION OF VARIOUSLY PROTONATED META-FREE PPC

\begin{tabular}{c|c}
\hline Protonated state & Heat of formation $(\mathrm{kJ} / \mathrm{mol})$ \\
\hline non-protonated (initial) & 1629.1 \\
mono-protonated & 2178.6 \\
di-protonated (adjacent pair) & 2990.2 \\
di-protonated (diagonal pair) & 3019.7 \\
tri-protonated & 4022.4 \\
tetra-protonated & 5216.8 \\
\hline
\end{tabular}

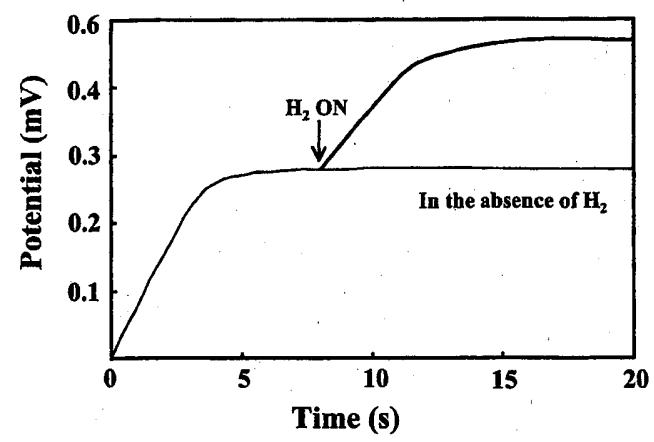

Fig. 12. Thermoelectric power of the Cu-PPc sensor upon introduction of $\mathrm{H}_{2}$.

against ambient gases. The effect of various gases was tested on the sensing characteristics with a flow rate of $2 \mathrm{l} / \mathrm{min}$ : $\mathrm{CH}_{4}(1 \%), \mathrm{CO}(2 \%), \mathrm{CO}_{2}(24 \%)$, NO $(0.6 \%), \mathrm{SO}_{2}(0.2 \%)$, saturated vapor of $\mathrm{CH}_{3} \mathrm{OH}, \mathrm{C}_{2} \mathrm{H}_{5} \mathrm{OH}$, and $\mathrm{H}_{2} \mathrm{O}$ moisture. No noticeable change in electrical resistivity (less than $0.1 \%$ ) was recognized for these gases. In addition, $100 \% \mathrm{H}_{2}$ was also introduced, while the above gases flowed through the chamber. Only normal change in resisitivity reduction was observed due to $\mathrm{H}_{2}$, quite independent of the ambient gases. This indicates that the sensor is free from the influence of ambient gases.

However, it is important to note that the present sensor is also quite sensitive to protons (i.e., acids), since our sensor has been transformed from an acid sensor to the $\mathrm{H}_{2}$ sensor as stated in Section I. In order to discriminate $\mathrm{H}_{2}$ from protons, we use a composite device with two sensors with or without $\mathrm{Pd}$ (or Pt). The sensor without $\mathrm{Pd}$ is sensitive to protons but insensitive to $\mathrm{H}_{2}$. On the other hand, the sensor with $\mathrm{Pd}$ is only sensitive to $\mathrm{H}_{2}$. Then, $\mathrm{H}_{2}$ can be detected when the sensor with $\mathrm{Pd}$ responds; whereas an acid is detected when both sensors operate.

\section{Determination of the Charge Carrier and the Operation Principle of the Sensor}

As presented in Section I, the sensor operates in two steps: carrier formation and carrier transport. The former process assumes the electron conduction as illustrated in Fig. 2(b): $\mathrm{H}_{2} \rightarrow$ $\mathrm{H}+\mathrm{H}$, and $\mathrm{H}+$ pyridyl ring $\rightarrow$ protonated pyridyl ring $\left(\mathrm{N}^{+} \mathrm{H}\right)$ $+\mathrm{e}^{-}$. In order to support the present mechanism, it is necessary to verify the electron conduction.

Fig. 12 shows the change in thermoelectric power of the $\mathrm{Cu}-\mathrm{PPc}$ sensor upon introduction of $\mathrm{H}_{2}$ as a function of time. A positive potential appears at the hot end (see Fig. 6) as soon as the contact is made between the soldering iron and the surface of sample. Then, upon introduction of $100 \% \mathrm{H}_{2}$, an additional increase in positive potential is recognized. These results indicate evidently that the charge carrier is due to electrons. The present result directly supports the operation principle of the $\mathrm{H}_{2}$ gas sensor.

Finally, it is important to note that $\mathrm{CuPc}$ is widely known as the hole conductor [16], [17]; whereas $\mathrm{Cu}-\mathrm{PPc}$ is found to be an electron conductor. The difference in molecular structure between $\mathrm{CuPc}$ and $\mathrm{Cu}-\mathrm{PPc}$ consists only in the ring at the corner: phenyl or pyridyl ring. In the case of $\mathrm{CuPc}$, the charge transfer level $\left(\mathrm{O}_{2} / \mathrm{O}_{2}^{-}\right)$is located near the valence band. Therefore, the adsorption of $\mathrm{O}_{2}$ on $\mathrm{CuPc}$ gives rise to a hole in the valence band even at room temperature [17]: $\mathrm{O}_{2}$ (ads) $+\mathrm{e}^{-}$(valence band) $\rightarrow \mathrm{O}_{2}^{-}$(ads) $+|\mathrm{e}| \cdot$ (valence band). Replacement of the phenyl ring by pyridyl rings might presumably shift the charge transfer level $\left(\mathrm{O}_{2} / \mathrm{O}_{2}^{-}\right)$upward so that the charge transfer cannot take place with thermal energy at room temperature. This ends up with electron conduction of $\mathrm{Cu}-\mathrm{PPc}$.

\section{E. Some Aspects of Intelligent Sensors}

Our sensor can easily be fabricated on a glass substrate with ITO as well as on a polyethylene terephthalate (PET) with ITO. In this sense, a flexible $\mathrm{H}_{2}$ sensor is possible. Furthermore, our sensor is also sensitive to acid, as described in Section III-C. The composite device with two small sensors with or without $\mathrm{Pd}$ (or Pt) (see Section III-C) can serve as a sensor for both $\mathrm{H}_{2}$ and acids.

\section{CONCLUSION}

High-performance $\mathrm{H}_{2}$ gas sensor has been developed that utilizes the proton affinity of copperphthalocyanine derivative with pyridyl rings ( $\mathrm{Cu}-\mathrm{PPc})$. Remarkable reduction in electrical resistivity by three orders of magnitude even under $0.01 \% \mathrm{H}_{2}$ is achieved at room temperature. Furthermore, the process is reversible, and the response is quite fast. The charge carrier is found to be electrons on the basis of the Seebeck effect. No noticeable effect of ambient gases $\left(\mathrm{CH}_{4}, \mathrm{CO}, \mathrm{CO}_{2}, \mathrm{NO}, \mathrm{SO}_{2}, \mathrm{CH}_{3}\right.$ $\mathrm{OH}, \mathrm{C}_{2} \mathrm{H}_{5} \mathrm{OH}$, and $\mathrm{H}_{2} \mathrm{O}$ moisture) on the sensor is recognized.

\section{REFERENCES}

[1] M. L. Perry and T. F. Fuller, "A historical perspective of fuel cell technology in the 20th century," J. Electrochem. Soc., vol. 149, pp. S59-S67, 2002.

[2] P. T. Moseley, "Solid state gas sensors,". Meas. Sci. Technol., vol. 8, pp. 223-237, 1997.

[3] J. B. Miller, "Catalytic sensors for monitoring explosive atmospheres," IEEE Sensors J., vol. 1, pp. 88-93, 2001.

[4] A. Katsuki and K. Fukui, " $\mathrm{H}_{2}$ selective gas sensor based o $\mathrm{SnO}_{2}$, , Sensors and Actuators, vol. 52, pp. 30-37, 1998.

[5] R. C. Huges and W. K. Schubert, "Thin films of Pd/Ni alloys for detection of high hydrogen concentrations," J. Appl. Phys., vol. 71, pp. 542-544, 1992

[6] K. Yamanaka, H. Cho, and Y. Tsukahara, "Precise velocity measurement of surface acoustic waves on a bearing ball," Appl. Phys. Lett., vol. 76, pp. 2797-2799, 2003.

[7] W. Herbst and K. Hunger, Industrial Organic Pigments. Weinheim: VCH, 1993, pp. 418-446, 550-553.

[8] J. Mizuguchi, "Solution and solid state properties of 1,4-diketo-3,6bis-(4'-pyridyl)-pyrrolo-[3,4-c]-pyrrole on protonation and deprotonation," Ber Bunsenges. Phys. Chem., vol. 97, pp. 684-693, 1993.

[9] H. Takahashi and J. Mizuguchi, "Hydrogen gas sensor utilizing a high proton affinity of pyrrolopyrrole derivatives,"J. Electrochem. Soc., vol. 152, pp. H69-H73, 2005.

[10] H. Takahashi and J. Mizuguchi, "Carrier generation and carrier determination in dipyridyldiketopyrrolopyrrole-based $\mathrm{H}_{2}$ gas sensors," $J$. Appl. Phys., to be published.

[11] K. Sato, K. Hino, H. Takahashi, and J. Mizuguchi, "Hydrogen gas sensors based upon perylene-imide derivatives," IJISTA, in press. 
[12] J. Mizuguchi, "An improved method for purification of $\beta$-copperphthalocyanine," Cryst. Res. Tech., vol. 16, pp. 695-700, 1981.

[13] J. M. Ziman, Principles of the Theory of Solids, 2nd ed. Cambridge, U.K.: Cambridge Univ. Press, 1972, pp. 235-239.

[14] K. Seeger, Semiconductor Physics, 3rd ed. Berlin, Germany: Springer-Verlag, 1985, pp. 78-91.

[15] WinMOPAC, ver. 3.5, Fujitsu, Ltd., Kanagawa, Japan

[16] F. Gutmann and L. E. Lyons, Organic Semiconductors. New York: Wiley, 1967, ch. 6 .

[17] J. Mizuguchi, "Effect of oxygen and hydrogen on transient photocurrents in evaporated thin films of $\beta$-copperphthalocyanine," Jpn. J. Appl. Phys., vol. 20, pp. 713-719, 1981.

T. Hoki received the B.E. and M.E. degrees in applied physics from Yokohama National University, Yokohama, Japan, in 2004 and 2006, respectively. In the master's course, he was involved in structure analysis of quinacridone pigments, as well as in development of hydrogen gas sensors using copperphthalocyanine derivatives.

Since 2006, he has been with Rohm Company, Ltd.
H. Takahashi received the B.E. degree in electronic engineering from Waseda University, Tokyo, Japan, in 1968 and the Dr. of Engineering degree from Yokohama National University, Yokohama, Japan, in 2005.

He worked at Sony Corporation from 1968 through 2004. He is currently a Visiting Scientist at Yokohama National University.

S. Suzuki received the B.S. and M.E. degree in applied chemistry and the Dr. of Engineering degree from Yokohama National University, Yokohama, Japan, in 1964, 1966, and 2004, respectively.

He was with Toyo Ink Manufacturing Company, Ltd., from 1966 to 1999. From 1999 through 2004, he was President of the Toyo Ink Engineering Company, Ltd. He is currently a Visiting Scientist at Yokohama National University.

J. Mizuguchi received the B.S. degree in chemistry from Sophia University, Tokyo, Japan, in 1970, the Dr. of Science degree from the University of Tokyo, Tokyo, in 1982, and the Venia Docendi degree from the University of Bern, Bern, Switzerland, in 1994.

He worked at Sony Corporation Research Center from 1970 to 1985 and at Ciba-Geigy AG (Switzerland) from 1985 to 1995. He is a Professor of Materials Science at Yokohama National University, Yokohama, Japan, since 1995. 